\title{
Shortage of doctors in rural health centers: Empirical evidence from Gujarat
}

\author{
Somen Saha and Harshad Rathod ${ }^{1}$ \\ ${ }^{1}$ Somen Saha (ssaha@iiphg.org) is a faculty with Indian Institute of Public Health Gandhinagar, Gujarat. Harshad Rathod \\ (dr_rathod@yahoo.com) is a Block Health Officer at Prantij, Sabarkantha, Gujarat.
}

\section{A BSTRACT}

Background: Shortage of medical graduates and post graduates in the government sector, especially in rural areas is a major problem in India. Rural and remote areas of Gujarat are facing shortages of MBBS graduates and post graduates. About 25 percent of posts in the health and family welfare department are vacant. The worst affected is the class I positions where over 40 per cent posts were vacant. This study is an attempt to identify the motivating and de-motivating factors, in joining government service, among the medical graduates and post graduates in Dahod district of Gujarat. Methods: Questionnaires were prepared for two groups of doctors: those who are in government services; those who left the government services. The questionnaire included both item wise response and likert scale questions. 36 in-service medical professional and 19 private doctors participated in the study. Results: $44 \%$ of in service professionals from urban areas are working in urban areas, while $56 \%$ of them are working in rural areas. On the contrary, only $15 \%$ of the in-service professionals from rural areas are working in an urban area, with majority of them (84\%) are posted in a rural area. In services doctors believe that job security is more in government sector as compare to private sector. Variables like work environment, accountability, career development, social recognition and remuneration is less than satisfactory in government service. Conclusion: The decision to practice in rural areas is the result of complex interaction between a number of factors including individual background, service infrastructure, human resource practices including opportunity for career growth, remuneration, and autonomy. The study provide strong indication that promoting students from rural background to pursue medical education through reservation or scholarship may go a long way in addressing shortage of medical professional in rural areas. Following motivational factors can help in retention of skilled man power in government: positive work environment, adequate remuneration/compensation, career development and a supportive health system, adequate compensation and working conditions. Time bound promotion can be one of the important factors for retention of doctors in government sector.

Keywords: Rural, Doctors, Shortages, Gujarat

\section{INTRODUCTION}

Human resources are central to all public health systems and a considerable share of resources allocated to public health goes towards it. Insufficient number of doctors in government health care service throughout the country, both general medical officers and specialist, has been a matter of concern. Census estimates shows that approximately 2.17

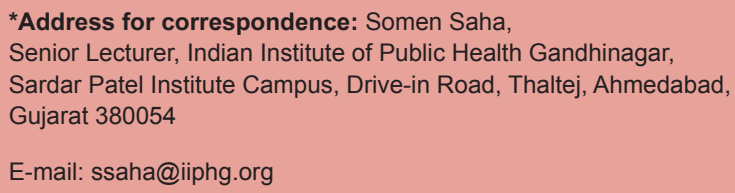

DOI: 10.5530/ijmedph.2.3.11 million health work force in India in 2005, which translate in density of approximately 20 health workers per 10,000 populations. ${ }^{1}$ Among the different categories of health workers, allopathic physicians shared 6 doctors per 10,000 populations. ${ }^{2}$ Among this shared number approximately 3.9 are qualified physician. The distribution of health workers was heavily skewed towards urban areas with typically $60 \%$ of the health workers including most categories, having urban residence. The allopathic physicians in urban areas were four times that of rural areas.

Figure no. 3 shows the distribution of health workforce by sector. Figure 3 and Table 1 shows that in rural area there is big shortfall in public sector compared to private sector. Approximately $18 \%$ of total doctors are in government sector and remaining $92 \%$ of doctors doing private 
Table 1: Status of recruitment to joining government service

\begin{tabular}{lccc}
\hline Designation & Recruited & Joined* & Not join \\
\hline Class I (specialist) & 642 & 161 & 481 \\
Allopathic physician & 3150 & 944 & 2206 \\
BAMS & 662 & 499 & 163 \\
BHMS & 743 & 423 & 320 \\
Total & 5197 & 2027 & 3170 \\
\hline
\end{tabular}

*Appointed up to $31^{\text {st }}$ Jan 2010

Source: Sandesh Newspaper editorial on $3^{\text {rd }}$ April 2010.

practice. In urban area $24 \%$ of doctors are in government sector and $76 \%$ of doctors doing private practice.

Despite 229 medical colleges with an annual capacity of 25,600, nearly 700 PHCs are without doctor the existing CHCs have a high shortfall of specialist manpower, such as obstetricians and gynecologists (56\%) pediatricians $(67 \%)$, surgeons $(56 \%)$ and medical specialists (59\%), with no provision of anesthetists. ${ }^{3}$

Figure 1 shows the availability of doctors per 1000 population. According to this data there are only 0.47 doctors available per 1000 population in India. The world wide figure is 1.5 doctors per 1000 population.

A recent study conducted by the Indian Council of Medical Research (ICMR) in 23 districts in 14 states showed that only $52 \%$ of the auxiliary nurse-midwives and $57 \%$ of the medical officers stay at their place of posting (ICMR 1997). Many of the staff prefer to and are allowed to stay in a nearby city or town from where they commute to their place of work. This means that the health services are not available 24 hours at the health centers as planned. Most staff spends only three to four hours at their place of work on a working day of eight hours (Mavalankar et al 1998; Ghosh 1994). Allopathic physicians are highly concentrated in urban (13.34) compared to rural (3.28) areas. In general, there are a little more than four times as many allopathic

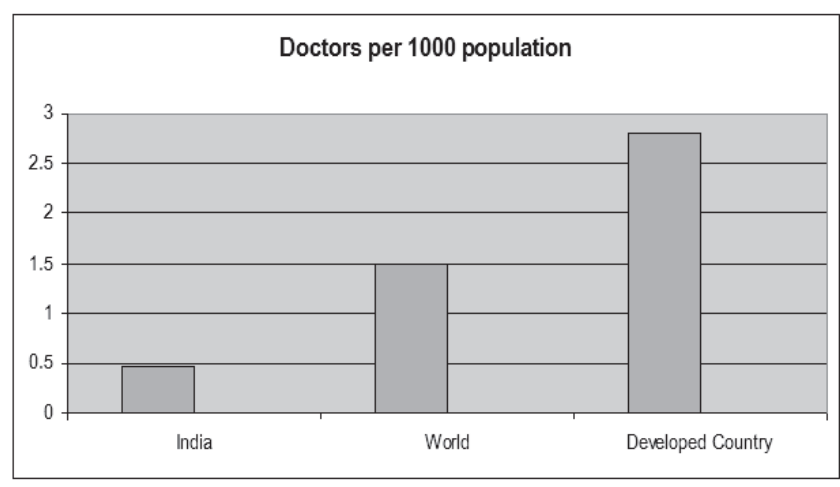

Figure 1: Availability of doctor per 1000 population Source: www.indiaonline.in/health/Health-Statistics.aspx. Access on 21 June 21, 2010. physicians in urban compared to rural areas (Census 2001). Government estimates also suggest that the distribution of health workers is heavily skewed towards urban areas. The total number of allopathic doctors in the government service is approximately 77,000 (CBHI 2006). According to the Medical Council of India, there are a total of 660,856 doctors in the country. It follows from this that there are approximately 583,900 doctors practice in private sector.

\section{SCENARIO OF PUBLIC HEALTH PROFESSIONAL IN GUJARAT}

One of the prime reasons behind the poor health status in Gujarat, despite good socio-economic index, is the insufficient number of doctors in the public health system, especially in the rural areas. The state is facing the shortage of medical professional despite having 13 medical colleges running in the state. A recent data from government source mentions about 25 per cent of posts in the health and family welfare department of Gujarat is vacant. The worst affected is the Class 1 positions where over 40 per cent posts are vacant (TNN 2010). The number of medical colleges in Gujarat increase markedly since 1980. Currently the state has 13 medical colleges, compared to only 5 in the 80 s. Still the state is suffering from shortage of medical professionals in the public sector which is suggestive of that many factors like: migration, join private clinic, not satisfied with government etc, affecting the shortage of graduate in government service.

Several factors contribute to the shortage of government doctor. The recruitment and transfer policy is not followed thoroughly which is contributory factor for the lack of motivation among doctors to provide services in rural areas. Postgraduate students are recruited by the governments and placed at CHCs where the skills acquired by them during post graduation are of little relevance. There is almost always a mismatch of skill gynecologists is posted at a $\mathrm{CHC}$ where there is no anesthetists resulting in the underutilization of skills. In many state (such as orissa, Bihar, Uttar Pradesh, Rajasthan) a Medical officer gets the first promotion after 
15-20 years of service. There are many doctors who continue to remain medical officer without promotion while there counterpart in civil service might have been promoted from sub divisional magistrate to special secretary or even secretary and from account officer to financial advisor. Career stagnation affects morale. The most de-motivating factor is the lack of appropriate facilities and required inputs to enable a qualified doctor to do his best for his patient and derive job satisfaction (MOHFW 2005). In addition, lack of decent housing facilities and educational facilities for their children are further contributory factors to the reluctance to work in rural and underserved areas.

The joint learning initiative framework referred to in recent NRHM report list nine key areas for action: numeric adequacy, skill mix, social outreach, satisfactory remuneration, work place environment, system support, appropriate skill, learning and training and leadership and entrepreneurship. These are linked to three objectives: Coverage, motivation and competence (Berman 2009). Mavalankar (1998) mentions the following challenges in retention of medical officers: fund flow and other financial matters, political factors, work culture, accountability, PHC infrastructure, organizational work load etc. There is no uniform system requiring the senior most positions in the Department of Health and Family Welfare to have any public health qualification or management training. Management training in the primary health care system is weak (Mavalankar 1998) and programmes are run in a very bureaucratic and hierarchical fashion without the application of modern concepts of management or public health. Maheshwari, Bhat and Saha (2006) identified the following initiatives to foster a development climate among the health officials of Gujarat: providing opportunities for training, professional competency development, developing healthy relationship between superiors and subordinates, providing useful performance feedback, and recognizing and rewarding performance. The authors observed for reform process in the health sector to succeed, there is a need to promote high involvement of medical officers. There is a need to invest in developing leadership quality, supervision skills and developing autonomy in its public health institutions.

The state health department has a system of compulsory bond for the MBBS doctors for three years to perform duty in government sector. In Gujarat doctors are not willing to join the government sector even after getting recruitment from government. To cope up with this shortage, Government of Gujarat has a system to conduct interview every Tuesday for medical officers: both Class I and Class II. As evident from Table 1, only $25 \%$ of class I position, $30 \%$ of allopathic positions joined service, with overall joining being 39\%. This dismal uptake of public service requires close understanding.

To overcome the shortage of doctors in public health system, the state has from time to time used innovative partnership arrangements to help private practitioner in rural area. The latest being Chiranjivi scheme which is a partnership arrangement with private practitioners to increase institutional deliveries in the state. However the report of NRHM common review mission (2007) mention that through the Chiranjivi scheme has yielded visible result in increasing deliveries capacity, but in underserved area there would be no escape from increasing public provision.

There is a limited study, with particular focus on the rural areas of Gujarat, to identify the factors affecting decision of a medical graduate to join and stay in a government service, viz a viz private practice or joining a private hospital. This became the rationale for this study to understand the factors affecting shortage of qualified medical professional in government service, especially in rural areas.

\section{STUDY OBJECTIVE AND SITE SELECTION}

The objective of this study is to identify the factors affecting shortage of qualified medical graduates and post graduates in Dahod district.

Dahod district was chosen for the study where $45 \%$ of sanctioned positions are filled by MBBS graduates and $22 \%$ filled by specialists. Dahod district is the border district of Gujarat state. The district is hilly and one of the backward area of the state. Working in this district is challenging because of geographical situation, and poor infrastructure.

As per the data available for Dahod district, only $45 \%$ of medical graduates are available in PHC's and only 62.5\% in CHC and Civil Hospital. ${ }^{4}$ Moreover, only $22 \%$ specialists are available in $\mathrm{CHCs}$ which is a significant and rationale to do the study in this district. In Dahod there are 7 block and 58 PHC's, and 10 CHC's and 2 Civil Hospitals.

\section{RESEARCH QUESTION}

This paper examines the motivation of health officials in the Dahod district of Gujarat state. Accordingly, the problem statement was what the factors are affecting motivation of medical officers to be or not to be in government sector. 


\section{METHODOLOGY}

Two groups of medical professionals were interviewed in the study:

i. Medical professionals working in government sector.

ii. Medical professional who have ever been in government sector.

It was expected that the second group would highlight the de-motivating factors leading to decisions to leave service.

\section{STUDY POPULATION}

36 medical graduates from government sector and 19 medical graduates working in the private sector selected from 7 taluka of Dahod district were interviewed. Sample size from each taluka varied depending upon the availability and willingness to participate in the study (Table 2).

\section{STUDY DESIGN}

The questionnaires for government doctors included 9 human resource $(\mathrm{HR})$ practice variables derived from 27 questions. The dimensions for the questionnaire were based on review of literature, and validated through a brainstorming exercise among a group of medical doctors, both from public and private sector. The following variables were finally measured: job security, accountability, confidence, work place environment, social recognition, career development, satisfactory remuneration, family motivation, remuneration as compare to other sectors.

The questionnaire was divided into two parts. Part A of questionnaire included questions about their personal and organizational details. Age, qualification, permanent and current residence, work experience, and gender were the main personal detail items. Age and experience items were measured in number of years, while permanent, current address and place of posting were categorized as urban or rural. Part
$\mathrm{B}$ of the questionnaire contained 27 items measuring the human resource practices in the respondents' organization. The items under each group were measured using a fivepoint (1- strongly disagree to 5- strongly agree) likert scale. After combining theoretically similar variables, and removing redundant variables, 9 factors were extracted. The items were measured on a five point likert scale. A likert scale measures the extent to which a person agrees or disagrees with the question. If varies from strongly disagree to strongly agree.

\section{ANALYSIS PLAN}

Analysis was done in two steps. In the first step, descriptive statistics was obtained for the HR practice variable scores and personal items. In the second steps, the HR practice variables were classified by permanent residence, current residence, place of posting, gender and qualification of the respondents. Further, Fisher's Exact Test (F-test) was done to test the hypothesis of no difference. This test was done using SPSS 16.0.

\section{ETHICAL CLEARANCE}

Informed written and verbal consent were obtained from the participants. The study design and questionnaire were reviewed and cleared by the ethical review committee at Indian Institute of Public Health Gandhinagar (IIPHG).

\section{LIMITATIONS}

The study has certain limitations to be considered in interpreting the results:

a. The study has limited sample size which limits generalization of the results. The observations in the study need to be validated with a larger sample size.

b. We relied on volunteer participation of doctors, which can have some biases in the respondent profile.

\section{Table 2: Number of respondent from 7 taluka's of Dahod district}

\begin{tabular}{lcccc}
\hline Name of taluka & No. of doctors in Public sector & \multicolumn{2}{c}{ No. of doctors in Private sector } \\
\hline Fatepura & Class-I & Class-II & Post Graduate & MBBS \\
Zalod & 0 & 3 & 0 & 01 \\
Garbada & 0 & 6 & 0 & 06 \\
Dahod & 0 & 2 & 0 & 0 \\
Dhanpur & 05 & 7 & 02 & 0 \\
Devgadh Baria & 0 & 1 & 0 & 0 \\
Limkheda & 03 & 6 & 0 & 06 \\
Total & 0 & 3 & 03 & 01 \\
\hline
\end{tabular}




\section{RESULTS}

\section{CHARACTERISTICS OF RESPONDENTS}

Out of all respondents, $70 \%$ were from government sector and remaining 30\% were from doctors from private sector. Among all respondent from government sector, $56.7 \%$ doctor's permanent residence is urban area, where as $43.3 \%$ doctor's permanent residence is rural area. $48.5 \%$ of government doctor's current residence is urban area and $51.5 \%$ of doctor's current resident is rural area.

Table 3 points at some of the interesting facts about preferences of medical professionals. Across in service (government) and ever been in service (private), majority of medical professionals hailing from rural areas are more likely to work in rural areas. This has a major policy implication in government's decision to address shortage of medical professionals in rural areas.

$44 \%$ of in service professionals from urban areas are working in urban areas, while $56 \%$ of them are working in rural areas. On the contrary, only $15 \%$ of the in-service professionals from rural areas are working in an urban area, with majority of them $(84 \%)$ are posted in a rural area. In case of private practitioners, the ratio of urban professionals working in urban and rural area is 40:60. Of the 8 private practitioners hailing from rural areas, all of them are working in a rural area.

Table 4 shows the comparative statement of current residence to work area. By current residence, it was meant to understand whether the medical professionals reside in or nearby the health center (for in-service doctors) or their work place (for private doctors). $32 \%$ of in-service doctors working in rural areas, reported that they commute from (currently residing) an urban area. On the contrary, $79 \%$ of in-service doctors currently residing in rural areas are actually working in rural areas. This is also true for private practitioners. Again this finding confirms the literature which suggests that many of the staff prefer to stay in a nearby city or town from where they commute to their place of work.

Table 5 shows the analysis of specialization to the choice of working place. For in service class I doctors 63\% are working in urban area and $37 \%$ of the doctors are working in rural area where as for class II doctors $32 \%$ are in urban area and 68\% are in rural areas. One of the reason for being at urban are for class I doctor is that most of the posts for class I are at district head quarter or in urban area where as most of the post for class II officer in rural area. The class II medical officers are posted at PHC's, CHC's, district hospitals and district head quarter.

\begin{tabular}{|c|c|c|c|c|c|c|c|}
\hline \multirow[t]{3}{*}{ In service } & \multicolumn{3}{|c|}{ Permanent residence Vs Working } & \multirow{3}{*}{$\begin{array}{c}\text { Ever been in } \\
\text { service }\end{array}$} & \multicolumn{3}{|c|}{ Permanent residence Vs Working } \\
\hline & & \multicolumn{2}{|c|}{ Working } & & & \multicolumn{2}{|c|}{ Working } \\
\hline & & URBAN & RURAL & & & URBAN & RURAL \\
\hline \multirow[t]{2}{*}{ Resident } & URBAN & 08 (44) & $10(56)$ & Resident & & $4(40)$ & $6(60)$ \\
\hline & RURAL & $2(15)$ & $11(84)$ & & RURAL & 0 & $8(100)$ \\
\hline
\end{tabular}

* Figures in the parenthesis indicate percentage

Table 4: Comparative analysis of respondent profile (current residence versus work place)

\begin{tabular}{|c|c|c|c|c|c|c|c|}
\hline \multicolumn{8}{|c|}{ Current residential address to Working place } \\
\hline \multirow[t]{3}{*}{ In service } & \multicolumn{3}{|c|}{ Current residence Vs Working } & \multirow[t]{3}{*}{ Ever been in service } & \multicolumn{3}{|c|}{ Current residence Vs Working } \\
\hline & \multicolumn{3}{|c|}{ Working } & & & \multicolumn{2}{|c|}{ Working } \\
\hline & & URBAN & RURAL & & & URBAN & RURAL \\
\hline \multirow[t]{2}{*}{ Resident } & URBAN & $13(68)$ & $6(32)$ & Resident & URBAN & $6(67)$ & $3(33)$ \\
\hline & RURAL & $3(21)$ & $11(79)$ & & RURAL & $0(0.00)$ & $9(100)$ \\
\hline
\end{tabular}

* Figures in the parenthesis indicate percentage

\begin{tabular}{|c|c|c|c|c|c|}
\hline In service & URBAN & RURAL & Ever been in service & URBAN & RURAL \\
\hline$\overline{\text { Class I }}$ & $5(63)$ & $3(37)$ & Specialist & $2(40)$ & $3(60)$ \\
\hline Class II & $9(32)$ & $19(68)$ & MBBS & $1(8)$ & $12(92)$ \\
\hline
\end{tabular}

* Figures in the parenthesis indicate percentage 
For private practitioner $40 \%$ specialist doctors responded to questionnaires from urban area and 60\% doctors from rural area whereas $92 \%$ MBBS graduates from rural area and remaining $8 \%$ doctors from urban area. This figure shows that most of the MBBS doctors choose rural area for their private practice.

\section{HR PRACTICE VARIABLES FOR IN-SERVICE DOCTORS}

Table 6 show the mean and standard deviation of nine HR practice variables. The job security (mean 4.07) is the only factors for which in service doctors are being in government sector. The mean score of accountability (mean: 3.46), confidence in work (mean: 3.31), and work place environment (mean: 3.19 ) are low for government doctors. The mean of other variables including social recognition, career development, satisfactory remuneration, family motivation, and comparative remuneration (compared to being in private sector) are below 3.0. These low score are causes of concern that needs to be addressed in addressing shortage of medical professionals in the public health sector.

\section{HR PRACTICE VARIABLES FOR IN-SERVICE DOCTORS}

Private Doctors, ever been in service, were asked about their experiences with government services. Table 7 presents the result. Career development scope, or lack of it, is rated as the most important factor (mean: 3.78), closely followed by in conducive work environment (mean: 3.74), and unsatisfactory remuneration (mean: 3.53).

\section{HUMAN RESOURCE PRACTICE SCORE BY PERMANENT RESIDENCE}

In this section, we present the result of human resource practice scores by permanent residence of the medical professional. In service professionals from urban areas scored better in social recognition, confidence, and remuneration compared to other sectors, while professionals from rural areas rated higher score in satisfactory remuneration, work environment, career development, motivation from family, and accountability issues. However, the difference in mean score between rural and urban residence is not significantly different at $95 \%$ confidence interval.

\section{HUMAN RESOURCE PRACTICE SCORE BY CURRENT RESIDENCE}

In this section, we present the result of human resource practice scores by current residence of the medical professional (Table 9). In service professionals from urban areas rate higher in job security, motivation from family, confidence, and remuneration compared to other sector. Professionals from rural area rate higher score in satisfactory remuneration, work environment, career development, social recognition, accountability measures. The difference

\begin{tabular}{lccc}
\multicolumn{2}{l}{ Table 6: Description of variables for in service doctors } \\
\hline HR Practice Variables & N & Mean & Std. Deviation \\
\hline Job Security & 36 & 4.07 & 0.70 \\
Accountability & 35 & 3.46 & 0.76 \\
Confidence & 36 & 3.31 & 0.84 \\
Work Place Environment & 36 & 3.19 & 0.52 \\
Social Recognition & 36 & 2.97 & 1.07 \\
Career Development & 28 & 2.85 & 0.74 \\
Satisfactory Remuneration & 32 & 2.72 & 0.64 \\
Family Motivation & 36 & 2.67 & 1.07 \\
Comparative Remuneration & 34 & 2.56 & 0.94 \\
\hline
\end{tabular}

\section{Table 7: Description of variables for private doctors (ever been in service)}

\begin{tabular}{|c|c|c|c|}
\hline Variable & $\mathbf{N}$ & Mean & Std. Deviation \\
\hline Lack of scope for career development & 19 & 3.78 & 0.72 \\
\hline Work environment not conducive & 19 & 3.74 & 0.45 \\
\hline Unsatisfactory remuneration & 19 & 3.53 & 1.07 \\
\hline De-Motivation & 19 & 3.06 & 0.98 \\
\hline Lack of job satisfaction & 19 & 2.53 & 1.26 \\
\hline
\end{tabular}


in mean score between rural and urban residence is not significantly different at 95\% confidence interval.

\section{HUMAN RESOURCE PRACTICE SCORE BY QUALIFICATION}

In this section, we present the result of human resource practice scores by educational qualification of the medical professional (classified as Class I \& II). Class I officials rate higher in work environment, motivation from family, confidence in profession, accountability in government sector, while Class II officials rated higher job security, satisfactory remuneration, Work environment, career development, social recognition, and remuneration compared to other sector. The difference in mean score between Class I and Class II officials is not significantly different at 95\% confidence interval.

\begin{tabular}{lcccc}
\multicolumn{1}{l}{ Table 8: Human Resource Practices by Permanent Residence } & & \\
\hline & Urban & Rural & F-value & Significance \\
\hline Job Security & 3.96 & 3.94 & 0.00 & 0.99 \\
Satisfactory Remuneration & 2.53 & 2.86 & 0.22 & 0.64 \\
Work Environment & 3.10 & 3.18 & 0.00 & 0.97 \\
Career Development & 2.77 & 2.86 & 0.25 & 0.62 \\
Motivation from Family & 2.35 & 3.09 & 0.86 & 0.36 \\
Social Recognition & 3.08 & 2.76 & 2.45 & 0.13 \\
Confidence & 3.50 & 3.26 & 3.65 & 0.50 \\
Accountability in Government Sector & 3.31 & 3.50 & 0.54 & 0.06 \\
Remuneration compared to other sector & 2.83 & 2.35 & & 0.47 \\
\hline
\end{tabular}

\section{Table 9: HR Practice variable by Current Residence}

\begin{tabular}{lcccc}
\hline Variables & Urban & Rural & F-value & Significance \\
\hline Job Security & 4.10 & 3.97 & 0.00 & 0.98 \\
Satisfactory Remuneration & 2.64 & 2.82 & 0.93 & 0.34 \\
Work Environment & 3.11 & 3.21 & 2.71 & 0.11 \\
Career Development & 2.54 & 3.03 & 0.00 & 0.92 \\
Motivation from Family & 2.73 & 2.63 & 0.03 & 0.85 \\
Social Recognition & 2.93 & 3.03 & 1.60 & 0.12 \\
Confidence & 3.43 & 3.24 & 2.86 & 0.21 \\
Accountability in Government Sector & 3.27 & 3.60 & 0.02 & 0.10 \\
Remuneration compared to other sector & 2.79 & 2.45 & & 0.90 \\
\hline
\end{tabular}

\section{Table 10: HR Practice variable by Educational Qualification}

Variables

Job Security

Satisfactory Remuneration

Work Environment

Career Development

Motivation from Family

Social Recognition

Confidence

Accountability in Government Sector

Remuneration compared to other sector

Class I

4.00

2.62

2.87

2.99

3.19

2.12

3.38

3.69

1.93

Class II

4.04

2.78

3.26

2.38

2.52

3.25

3.31

3.38

2.80

F-value

0.08

0.50

0.23

0.78

2.39

1.57

0.07

0.02

0.13
Significance

0.77

0.48

0.63

0.38

0.13

0.22

0.80

0.87

0.72

\section{Table 11: HR Practice variable by Gender}

\begin{tabular}{|c|c|c|c|c|}
\hline Variables & Male & Female & F-value & Significance \\
\hline Job Security & 4.06 & 4.12 & 0.37 & 0.54 \\
\hline Satisfactory Remuneration & 2.68 & 3.11 & 0.48 & 0.50 \\
\hline Work Environment & 3.18 & 3.25 & 0.99 & 0.32 \\
\hline Career Development & 2.83 & 2.99 & 0.50 & 0.49 \\
\hline Motivation from Family & 2.61 & 3.12 & 0.82 & 0.37 \\
\hline Social Recognition & 2.88 & 3.75 & 4.89 & 0.03 \\
\hline Confidence & 3.30 & 3.38 & 2.70 & 0.11 \\
\hline Accountability in Government Sector & 3.45 & 3.50 & 3.76 & 0.05 \\
\hline Remuneration compared to other sector & 2.52 & 2.87 & 2.23 & 0.15 \\
\hline
\end{tabular}




\section{HUMAN RESOURCE PRACTICE SCORE BY GENDER}

Females have statistically significant higher mean score on social recognition (3.75) than their male counterpart (2.88), and in accountability in government sector (3.50) compared to their male counterpart (3.45).

\section{CONCLUSION AND IMPLICATIONS}

Over all in-service medical professionals are not satisfied with their work. This was further confirmed by the response from private practitioners who have earlier worked in the government service. All the doctors including Class I and Class II are in government sector primarily because they believe that job security is higher in government sector. Job security is higher in those who are belonging to rural area.

Across in service (government) and ever been in service (private), majority of medical professionals hailing from rural areas are more likely to work in rural areas. This has an important policy implication in government's decision to address shortage of medical professionals in rural areas. There is an indication that, promoting students from rural background to pursue medical education through reservation or scholarship may go a long way in addressing shortage of medical professionals in rural areas. However, this finding needs to be validated with further review of records and studies with larger representative sample size. Respondent profile further confirms the literature that suggests that many of the staff prefer to stay in a nearby city or town from where they commute to their place of work.

MBBS graduates are also motivated for government job from their family member because there is more competition for doing private practice for MBBS doctors. However, there accountability are low in compared to Class I officers in government services. One of the reasons is that MBBS graduates having limited skill as compare to specialist.

Career development for in service MBBS graduates are very low in compare to Class I doctors because in service post graduation reserve seats are only $10 \%$ in Gujarat state and implemented since last 3 yrs. Social recognition is high in MBBS graduates those residing in rural area or head quarter. One of the reasons is the opportunity to do private practice in the locality.

Most of the government doctors give suggestions to deal with this problem are infrastructure including resident for staff and hospital is the prime requirement. Secondly they suggest proper system for working hour, time bound promotion, relevant work and for incentive for special work. Third number they give suggestion give for sufficient man power for relevant work. Salary comes on fourth number. Time bound promotion and special reservation seats for in service MBBS graduates are also they suggest.

Motivational issues such as a positive work environment, adequate remuneration/compensation, career development and a supportive health system, adequate compensation and working conditions to ensure retention of skilled workers in the health system; (iv) advancing competencies through education to develop appropriate attitudes and skills, and creating conditions for continuous learning.

There is no financial incentive for Working in rural, remote and tribal areas. Although the government is finding it increasingly difficult to motivate people to serve in the rural areas, they are yet to devise any incentive for rural posting.

Time bound promotion should be there because it is the important motivating factor for increase retention in government sector.

Our data indicate that the health sector is facing a number of challenges to ensure availability of medical professional in rural areas. For reform process in the health sector to succeed, there is a need to promote high involvement of medical officers. There was a need to invest in developing leadership quality, supervision skills and developing autonomy in its public health institutions. Till then, the department will continue to suffer from poor joining to recruitment ratio, and thereby under-staffed and poor indicators in health performance of the state.

\section{REFERENCES}

1. Berman P, Raha S, and Rao KD. Tackling health human resources challenges in India: initial observation on setting priorities for action. India health beat 2009; volume1.

2. Datta KK. Public Health Workforce in India, Career Pathway for Public Health Personnel. 2009; Page 24.

3. Health statistics in India. http://www.indiaonline.in/health/Health-Statistics. aspx. Accessed on 21 June, 2010.

4. Maheshwari S, Bhat R, and Saha S. Commitment among state health officials \& its implications for health sector reform: Lessons from Gujarat. Indian J Med Res 127, February 2008, pp 142-7.

5. Mavalankar D, Patel V. primary health care under panchayati raj in Gujarat perception of health service staff March 1998, pp 54-69 vol. 28 No. 1.

6. Raha S, Berman P, and Rao KD. Challenges in recruitment of doctors by government. India health beat. 2009; volume 1. Number 4.

7. Rao KD, Bhatnagar A, and Berman P. India's health work force: size composition and distribution. India health beat. 2005; volume 1. Number 3.

8. Rao KD, Bhatnagar A, and Berman P. Using multiple sources of information to estimate India's health work force. India health beat. 2005; volume1. Number 2.

9. TNN. Over 9K posts vacant in health dept. TNN, Times of India. Mar 28, 2010. 